\title{
Synergistic Effects of Arsenic Trioxide and Radiation: Triggering the Intrinsic Pathway of Apoptosis
}

\author{
Kave Moloudi ${ }^{1}$, Ali Neshasteriz ${ }^{* * 2}$, Arshad Hosseini ${ }^{3}$, Nazila Eyvazzadeh ${ }^{4}$, Mehdi \\ Shomali ${ }^{5}$, Samira Eynali ${ }^{6}$, Elahe Mirzaei ${ }^{7}$ and Asaad Azarnezhad ${ }^{*}{ }^{*, 9}$

\footnotetext{
${ }^{1}$ Radiation Sciences Department, Faculty of allied Medicine school, Iran University of Medical Sciences, Tehran, Iran;

${ }^{2}$ Radiation biology research center, Iran University of medical sciences, Tehran, Iran; ${ }^{3}$ Department of Medical Biotechnology, Faculty of allied Medicine, Iran University of Medical Sciences, Tehran, Iran; ${ }^{4}$ Radiation Research Center, Faculty of Paramedicine, AJA University of Medical sciences, Tehran, Iran;

${ }^{5}$ Radiology Department, Faculty of allied Medicine, Tehran University of Medical Sciences, Tehran, Iran;

${ }^{6}$ Medical physics and Biomedical Engineering Department, school of Medicine, Tran University of Medical Sciences,

Tehran, Iran; ${ }^{7}$ Microbiology Department, Faculty of Science, Islamic Azad University, Tehran, Iran;

${ }^{8}$ Cellular \& Molecular Research Center, Kurdistan University of Medical Sciences, Sanandaj, Iran; ${ }^{9}$ Department of Medical Genetics, School of Medicine, Tehran University of Medical Sciences, Tehran, Iran
}

Received 29 October 2016; revised 18 October 2016; accepted 1 January 2017

\begin{abstract}
Background: Arsenic trioxide (ATO) has been reported as an effective anti-cancer and a US Food and Drug Administration (FDA) approved drug for treatment of some cancers. The aim of this study was to determine the underlying apoptosis molecular and cellular mechanisms of ATO in the presence or absence of ionizing radiation (IR) in vitro in the glioblastoma multiforme (GBM) cell line, U87MG. Methods: Cells were treated by different concentrations of ATO either in presence or absence of IR. Viability and apoptosis pathway of both treated and control groups were evaluated using MTT assay and the expression analysis of $B a x, B c l-2$, and caspase-3 genes, respectively. All treatments were performed on 100- $\mu \mathrm{m}$ diameter spheroids. Results: Results showed a significant reduction in the survival of the cells in all treated groups. As expected, cell survival was much less in combination treatment than treatment with only ATO. Moreover, combination therapy made Bax and caspase-3 up-regulated and $\mathrm{BCl}-2$ down-regulated. Conclusion: ATO and radiation had a synergistic apoptotic effect on GBM cells by up-regulation of caspase-3 and alteration of the Bax-BCl-2 balance; therefore, ATO may act as a potential anti-cancer agent against GBM cells through triggering the mitochondrial pathway of apoptosis. DOI: 10.18869/acadpub.ibj.21.5.330
\end{abstract}

Keywords: Arsenic trioxide, Radiation, Apoptosis, Glioblastoma, Spheroids

*Corresponding Author: Asaad Azarnezhad

Cellular and Molecular research center, School of Medicine, Kurdistan University of Medical Sciences, Sanandaj, Iran; Tel.: (+98-912) 9245469; Fax: (+98-21) 88953005; E-mail: Azarnezhad@gmail.com

** Co-corresponding author

\section{INTRODUCTION}

$\mathrm{I}$ $\mathrm{n}$ spite of many advances, cancer is one of the major problems in the area of public health ${ }^{[1]}$. Gliomas are the most common type of brain tumors and responsible for $15 \%$ of brain tumors ${ }^{[2]}$.
Unfortunately, these malignant tumors are poorly diagnosed and treated. The mortality rate of glioblastoma multiforme (GBM) is about 12,000 per year in the USA, and three per 100,000 people develop the disease a year ${ }^{[3,4]}$. The disease is more frequent in males and generally occurs in the sixth decade of life ${ }^{[5]}$. 
The standard treatment regimen of GBM includes surgery, followed by radiotherapy ${ }^{[5]}$. Nonetheless, due to innate aggression, chemo/radiation resistance, hypoxia, and blood-brain barrier, glioblastoma remains difficult to treat, and survival is only 14 months after $\operatorname{diagnosis}^{[6,7]}$. Unfortunately, the brain is very damageable against conventional therapy, and the total ionizing radiation (IR) dose essential to control the tumors is much more than normal brain tissue tolerance ${ }^{[8]}$. Radiotherapy is the method of choice to treat about $50 \%$ of cancers. However, its application and efficiency are limited because of the mentioned reasons. Thus, complementary methods and agents can be utilized to enhance sensitivity to radiotherapy and avoid such unfavorable outcomes.

With the hope of curing cancer either by eliminating a tumor or preventing cancer recurrence, X-ray therapy has been used in combination with curative intent ${ }^{[9]}$. Literature has revealed that the combination of IR with ATO (arsenic trioxide) is a more effective treatment ${ }^{[10]}$. ATO is a Food and Drug Administration approved drug employed for centuries to treat a variety of conditions, including psoriasis, syphilis, and rheumatism, and its derivatives have been used as anticancer agents for many years ${ }^{[11,12]}$. It has recently been investigated that ATO has an effective role in treatment of acute promyelocytic leukemia (APL) ${ }^{[13]}$. Chiu et al. ${ }^{[14]}$ have shown that ATO enhances the radiation sensitivity of androgen-dependent and -independent human prostate cancer cells via increasing reactive oxygen species level and autophagy. Some in vitro studies have disclosed that ATO exerts its anti-cancer effects through inhibition of tumor growth by increasing the levels of reactive oxygen species and inducing apoptosis ${ }^{[14,15]}$. Also, apoptotic and nonapoptotic cell death is induced by radiation therapy. DNA damage response system is the biological consequences of IR, leading to the activation of apoptosis $^{[16]}$

Apoptosis is a programmed cell death process in multicellular organisms and its deficiency is implicated in a wide range of diseases. One mechanism of anticancer function of IR and chemotherapy drugs is the induction of apoptosis ${ }^{[17]}$. Down-regulation of $\mathrm{Bcl}-2$ and up-regulation of caspase-3 have been suggested as the mechanisms of ATO for inducing apoptosis ${ }^{[18,19]}$. Furthermore, in an ATO-dependent apoptotic process, the mitochondrial permeability is directly affected and the reactive oxygen species would be generated ${ }^{[20]}$. There is some information on the ability of ATO in inducing extrinsic pathway mediated by Fas cell surface death receptor (Fas) and caspase- 8 activation in acute megakaryocytic leukemia ${ }^{[21]}$. Although the possible effects of ATO have been reported in some cancers such as APL, the exact mechanism of ATO function in GBM is not fully determined.

We hypothesized that ATO alone or in combination with IR would potentiate the efficacy of each other by increasing the apoptosis rate of cancerous cells. Therefore, an experiment was designed based on a three-dimensional culture system to assess the apoptotic effects of ATO alone and in combination with IR on spheroids of U87MG cell line in cellular and molecular level in vitro.

\section{MATERIALS AND METHODS}

\section{Cell culture}

Human glioblastoma cell line, U87MG, maintained in MEM (GIBCO, USA) supplemented with $10 \%$ FBS (GIBCO, USA), $500 \mathrm{U} / \mathrm{ml}$ penicillin (Sigma, USA), and $200 \mathrm{mg} / \mathrm{L}$ streptomycin (Biowest, USA) was obtained from Pasteur Institute of Iran (Tehran, Iran). Cells were cultured as a monolayer at a density of 200,000 cells $/ \mathrm{ml}$ in T-25 tissue culture flasks (SPL, USA) in an incubator (Memmert, Germany) in $5 \% \mathrm{CO}_{2}$ humidified atmosphere at $37^{\circ} \mathrm{C}$. To achieve $70-80 \%$ of confluency and ensure to maintain cells in the logarithmic phase of growth, cells were trypsinated (1 $\mathrm{mM}$ EDTA/0.25\% Trypsin (w/v), Sigma, USA) and then sub-cultured . Cell viability $>97 \%$ was confirmed by trypan blue staining. Spheroids of uniform size and diameter from 450 to $550 \mu \mathrm{m}$ were produced using the liquid overlay technique. U87MG cells $\left(5 \times 10^{5}\right)$ were seeded in 100-mm dishes coated with a thin layer of $1 \%$ agar (Bacto Agar, Difco, Detroit, MI, USA) in 10 ml MEM supplemented with 10\% FBS and incubated in the above described condition for one month. Half of the culture medium was replaced with fresh medium twice per week.

\section{Drug-radiation treatment}

ATO (MW: $164.84 \mathrm{~g} / \mathrm{mol}$ ) (KANTO CHEMICAL Co, Japan) was dissolved in $1 \mathrm{M} \mathrm{NaOH}$, as the stock solution, and diluted to $10 \mathrm{mM}$ with double-distilled water prior to use. Treatment of U87MG spheroids was performed with ATO either with or without X-ray. In combination, U87MG spheroids in approximately 100 $\mu \mathrm{m}$ of diameters were treated by ATO $(2 \mu \mathrm{M}$ and $5 \mu \mathrm{M}$ diluted in growth medium, $\mathrm{pH}$ 7.0-7.4) for one volume doubling time (VDT, $54.7 \mathrm{~h}$ ). IR was then performed with $6 \mathrm{MV}$ X-rays using a linear accelerator (Linac 600, GMV; Varian Medical Systems; USA) at a dose rate of $4 \mathrm{~Gy} / \mathrm{min}$. An additional $2 \mathrm{~cm}$ tissue-equivalent bolus was placed on the top of a culture flask to ensure electronic equilibrium, and $10 \mathrm{~cm}$ of tissue-equivalent material was placed under the flask to obtain full backscatter. 


\section{MTT assay}

MTT assay was used to measure the cell viability for ATO treatment alone or in combination with IR. In order to prepare single cells, spheroids were trypsinized with $300 \mu \mathrm{l}$ trypsin in 5 minutes after one VDT. Then the medium was discarded, and the cells were washed with PBS and 10,000 cell $/ \mathrm{ml}$ seeded in 96-well polystyrene tissue culture plates. The cells were then placed in a humidified $5 \% \mathrm{CO}_{2}$ incubator at $37^{\circ} \mathrm{C}$ for $24 \mathrm{~h}$. After incubation, medium was removed, and $20 \mu \mathrm{L}$ aliquots of MTT solution $(5 \mathrm{mg} / \mathrm{ml}$ in PBS, Sigma, USA) were added to each well and re-incubated at $37^{\circ} \mathrm{C}$ for $4 \mathrm{~h}$. Next, $200 \mu \mathrm{L}$ of the supernatant culture medium was carefully aspirated, and $200 \mu \mathrm{L}$ aliquots of DMSO were added to each well to dissolve the formazan crystals, followed by 10-min incubation to dissolve air bubbles. The culture plate was placed on a microplate reader (Biotex, Houston, Texas, USA) and shaked for $20 \mathrm{~min}$, and absorbance was then measured at $570 \mathrm{~nm}$. The amount of color produced is directly proportional to the number of the viable cells. All assays were performed in eight replicates for each concentration, and each assay was repeated at least two times. Cell viability rate was calculated as the percentage of MTT absorption as shown in the following equation: \% survival=(mean experimental absorbance $) /($ mean control absorbance $) \times 100$.

\section{Analysis of cell morphology and apoptosis}

Annexin-V-FLUOS staining Kit (Roche Life Science, Germany) and Type Direct fluorescence staining were used for flow cytometric or microscopic analysis of apoptotic cells with membrane alterations (phosphatidylserine translocation) and differentiation of apoptotic from necrotic cells. In this light, different treated groups of spheroid cells were singled and washed with PBS and centrifuged at $180 \times \mathrm{g}$ at $4^{\circ} \mathrm{C}$ for 5 min. The cells were then incubated in a binding buffer containing Annexin-V-FLUOS and propidium iodide or Annexin-V-Alexa 568 (red dye) at $37^{\circ} \mathrm{C}$ for $10 \mathrm{~min}$. The stained cells were analyzed by fluorescence microscopy and flow cytometry. Necrotic cells take up propidium iodide and stained orange/green, while apoptotic cells stained green only.
Quantitative reverse transcription PCR (RT-qPCR)

A commercial RNA isolation kit (Jenabioscience, Germany) was used to extract total RNA from $4 \times 10^{6}$ cells of all groups (control, $2 \mu \mathrm{M}, 5 \mu \mathrm{M}, 4 \mathrm{~Gy}, 2 \mu \mathrm{M}+4$ $\mathrm{Gy}$, and $5 \mu \mathrm{M}+4 \mathrm{~Gy}$ ) according to the manufacturer's instructions. The quality and quantity of extracted RNA samples were assessed using the Nanodrop ND1000 (Nanodrop technologies, USA). Based on the quality and quantity of extracted RNA, $500 \mathrm{ng}-1 \mu \mathrm{g}$ RNA was converted into cDNA using AccuPower CycleScript RT PreMix (Bioneer, Korea) according to the manufacturer's instructions. Glyceraldehyde 3phosphate dehydrogenase (GAPDH), Bax, Bcl-2, and caspase-3 primer sequences were designed using the Primer3 software (version 0.4.0). GAPDH was used as an internal control to normalize the expression of target genes. Primers sequences designed for amplification of the targets are listed in Table 1.

\section{Data analysis}

The cycle threshold (CT) values provided by RTqPCR were used to calculate the relative fold expression according to the $2^{-\Delta \Delta \mathrm{CT}} \operatorname{method}^{[22]}$ and REST 2009 software (version 2.0). All experiments were performed in triplicate. Comparison between different groups was performed by using one-way ANOVA and the Dunnett's multiple test. A value of $P \leq 0.05$ was considered to be statistically significant. Data were expressed as the mean \pm SD.

\section{RESULTS}

\section{Growth curve}

Figure 1 shows the microscopic micrographs (Olympus Corporation of America) of spheroids in two different diameters. The growth curve of U87MG spheroids is shown in Figure 2. The VDT calculated from the curve was approximately 54.7 hours, which was consequently applied as the drug treatment time. Treatment with ATO at the presence and/or absence of 4 Gy x-ray was performed on spheroids with $100 \mu \mathrm{m}$ of diameter after one VDT.

Table 1. Nucleotide sequences of the primers used for real-time RT-PCR

\begin{tabular}{llllc}
\hline Gene & $\begin{array}{l}\text { Accession } \\
\text { number }\end{array}$ & Forward primer (5'-3') & Reverse primer (5'-3') & $\begin{array}{r}\text { Product } \\
\text { size (bp) }\end{array}$ \\
\hline Bax & NM_001291428 & GGACGAACTGGACAGTAACATGG & GCAAAGTAGAAAAGGGCGACAAC & 150 \\
Bcl-2 & NM_000633 & ATCGCCCTGTGGATGACTGAG & CAGCCAGGAGAAATCAAACAGAGG & 129 \\
Casapse-3 & NM_032991 & ATGGAAGCGAATCAATGGACTC & CTGTACCAGACCGAGATGTCA & 138 \\
GAPDH & NM-001289745 & GAGTCAACGGATTTGGTCGT & GACAAGCTTCCCGTTCTCAG & 185 \\
\hline
\end{tabular}



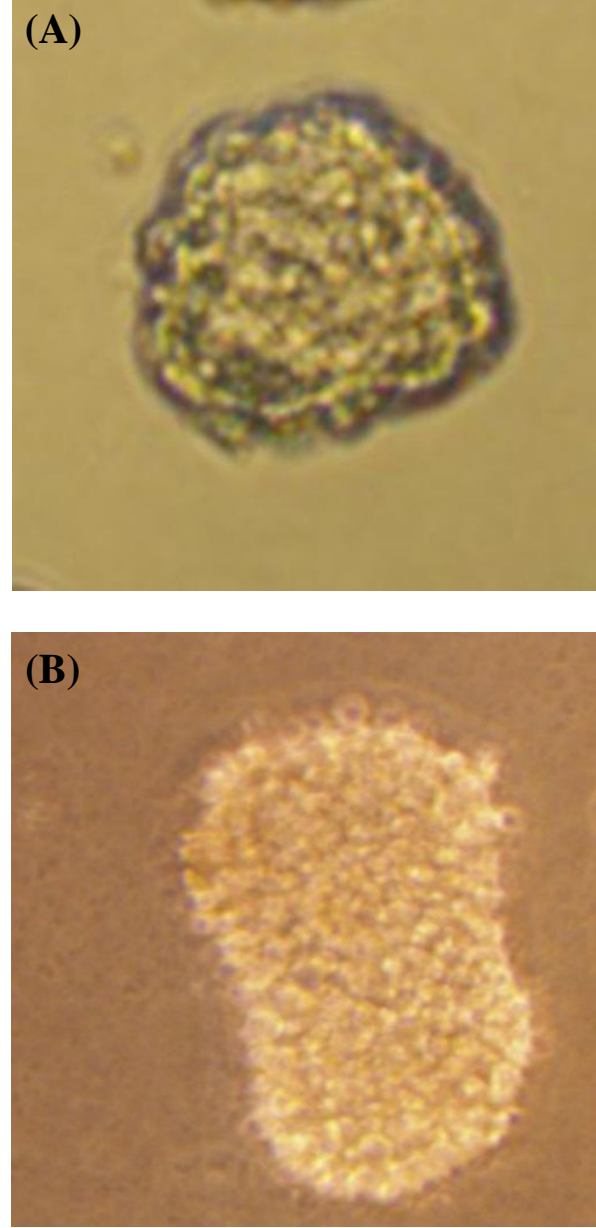

Fig. 1. The microscope micrographs of U87MG spheroids. A) $100-\mu \mathrm{m}$ spheroid at day 9; B) 300- $\mu \mathrm{m}$ spheroid at day 20

\section{Viability assessment}

Figure 3 shows the viability rate $(\%)$ of the treated groups after one VDT. As shown in the Figure, ATO significantly reduced the viability of U87MG cells. The viability of different groups containing control and the groups treated with $2 \mu \mathrm{M}$ ATO, $5 \mu \mathrm{M}$ ATO, $4 \mathrm{~Gy}$, $2 \mu \mathrm{M}+4 \mathrm{~Gy}, 5 \mu \mathrm{M}+4$ Gy was $100 \%, 83 \%, 56 \%$, $65.65 \%, 70.08 \%, 62.76 \%$, and $47.74 \%$, respectively.

\section{Real-time PCR results}

Comparison of the relative mean fold changes in gene expression levels of Bax, Bcl-2, caspase-3, and $\mathrm{Bax} / \mathrm{Bcl}$-2 ratio in U87MG spheroids treated by $\mathrm{ATO} \pm \mathrm{IR}$ in one VDT $(54.7 \mathrm{~h})$ is shown in Figures 4 and 5. Data indicated that the relative expression of Bax (Fig. 4A) was increased in all treated samples $(P \leq 0.05)$, as compared to the control group. In combination group (ATO and IR), $\mathrm{Bcl}-2$ was found to be up-regulated more significantly than single treatment group, indicating the synergistic effect of IR and ATO. According to Figure 4B, the expression of the anti-apoptotic $\mathrm{Bcl}-2$ gene was decreased in comparison to control group $(P<0.05)$. The $\mathrm{Bax} / \mathrm{Bcl}-2$ balance shows the degree of vulnerability of the cells to apoptosis. As demonstrated in Figure 5A, the combination of ATO and radiation induced more apoptosis than treatment with ATO or radiation alone. Also, the expression level of caspase-3 was increased in the presence of ATO and 4 Gy radiation (Fig. 5B). Alternatively, the combination of ATO+IR noticeably far increased the expression of caspase-3 in corresponding doses of ATO or 4 Gy alone.

\section{Cell morphology}

Fluorescence micrographs (Olympus Corporation, USA) and annexin-V-FLUOS staining kit were used to assay cell morphology. As it is shown in Figure 6, the apoptotic cells were visible in green and could be differentiated from necrotic cells after propidium staining.

\section{DISCUSSION}

GBM is the most common and the most malignant form of the glial tumors. Surgery, radiotherapy, chemotherapy, and immunotherapy are the common treatments for cancer in general and GBM in particular ${ }^{[23]}$. However, these approaches can extend the patients' survival only for few months ${ }^{[24,25]}$. Although radiotherapy is one of the widely-used treatments, it faces several disadvantages. The development of adjuvant agents can increase therapeutic effects of radiotherapy and decrease its drawbacks such as normal tissue damage and toxicity ${ }^{[26]}$. Therefore, a combination of different antitumor treatment modalities is advantageous in

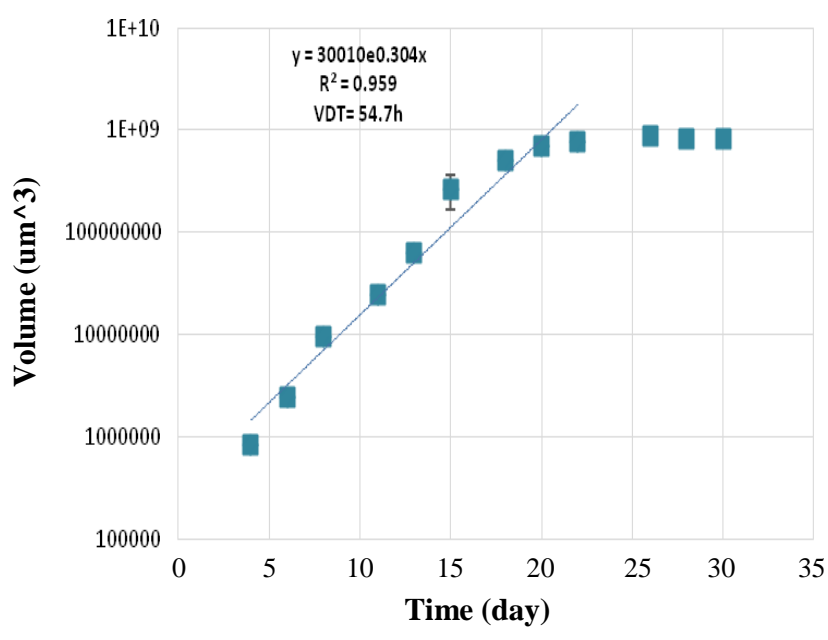

Fig. 2. The growth curve of the U87MG cell line in the spheroid cultures. The days 4 to 20 show the log phase of the curve and used to measure the volume doubling time $(54.7 \mathrm{~h})$. 


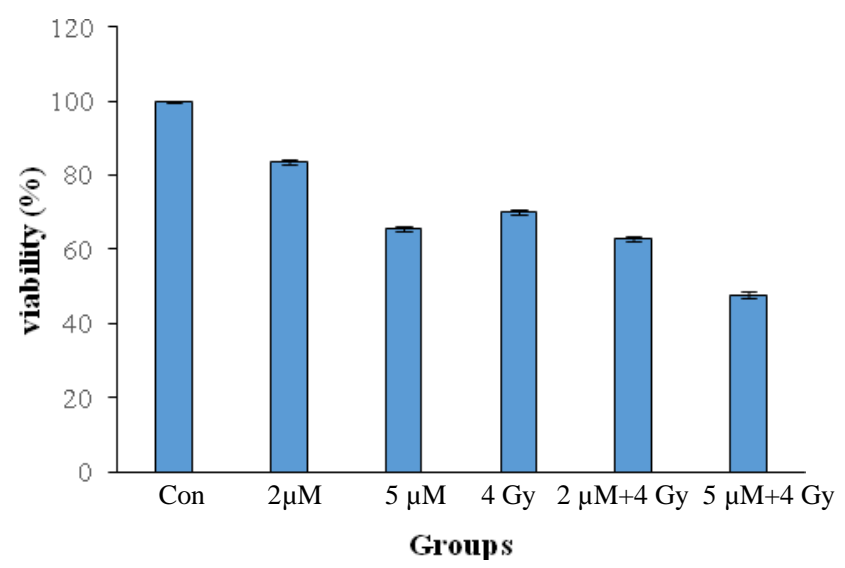

Fig. 3. Cell viability of spheroids U87MG cells after treatment with ATO alone or co-treatment with IR for $54.7 \mathrm{~h}$. Cell viability was determined based on the MTT assay results. Each point represents a mean value and standard deviation of three experiments with eight replicates per dose. Cell viability in treated groups were significantly different $(P \leq 0.05)$ compared to the control.

limiting the nonspecific toxicity ${ }^{[27]}$. Elucidation of the cellular and molecular mechanisms of the adjuvants functions is a major step to use them appropriately in clinic. Previous studies have indicated that ATO induces apoptosis and cell death ${ }^{[28,29]}$; however, its molecular mechanism in glioblastoma remains to be fully understood. These observations prompted us to evaluate the potential anticancer effects of ATO alone or in combination with IR on U87MG cell line and the possible activated molecular pathways of apoptosis.

Our cellular and molecular data revealed that ATO alone and more strongly in combination with IR decreased the cell survival through inducing apoptosis. In consistent with our findings, some phase II clinical trials have also shown that ATO alone has a limited activity and suggested that ATO should be used in combination with other therapeutic modalities such as radiotherapy ${ }^{[30]}$. Activation of a sensor' caspase, such as caspase- 8 or -9 following with the activation of other 'effector' caspases (e.g. caspase-3) is the probable mechanism of the synergism effect of ATO and X-ray that lead to cleavage of a large set of cellular proteins and ultimately destruction of the cell ${ }^{[31]}$.

Recent studies have indicated that low doses $(0.5-2$ $\mu \mathrm{M})$ of ATO induce apoptosis and cell cycle arrest in G2/M phases ${ }^{[28,29]}$, whereas high doses (more than IC50) have shown more cytotoxicity and low therapeutic effect. ATO in doses of 1-2 $\mu \mathrm{M}$ has revealed a great effect on APL with a low toxicity and good tolerance ${ }^{[32]}$. Nevertheless, IC50 of this drug has reported to be $5 \mu \mathrm{M}$ in several cell lines, such as APL and renal carcinoma ${ }^{[33]}$. In line with these findings, our results disclosed that ATO induces cell apoptosis and consequently decreases cell growth in vitro. MTT assay revealed that ATO decreases cell viability in a dose-dependent manner so that cell survival in $2 \mu \mathrm{M}$ and $5 \mu \mathrm{M}$ was $83.56 \%$ and $65.65 \%$, respectively. However, ATO combined with IR was more effective, and only $47.74 \%$ of the cells survived in exposure to 5 $\mu \mathrm{M} \mathrm{ATO}+4$ Gy IR. Morphologically, apoptosis is firstly characterized by a change in the refractive index of the cell ${ }^{[34]}$, followed by cytoplasmic shrinkage and nuclear condensation. In the present work, cell morphology study showed that ATO alone or in combination with IR possibly decreases cell growth and proliferation via inducing apoptosis.

Apoptosis is the major type of programmed cell death that is crucial for the balance between cell death and cell survival of normal cells; therefore, disturbing this equilibrium can lead to different diseases including cancer $^{[35]}$. There are two core pathways to induce apoptosis: extrinsic pathway that is triggered by
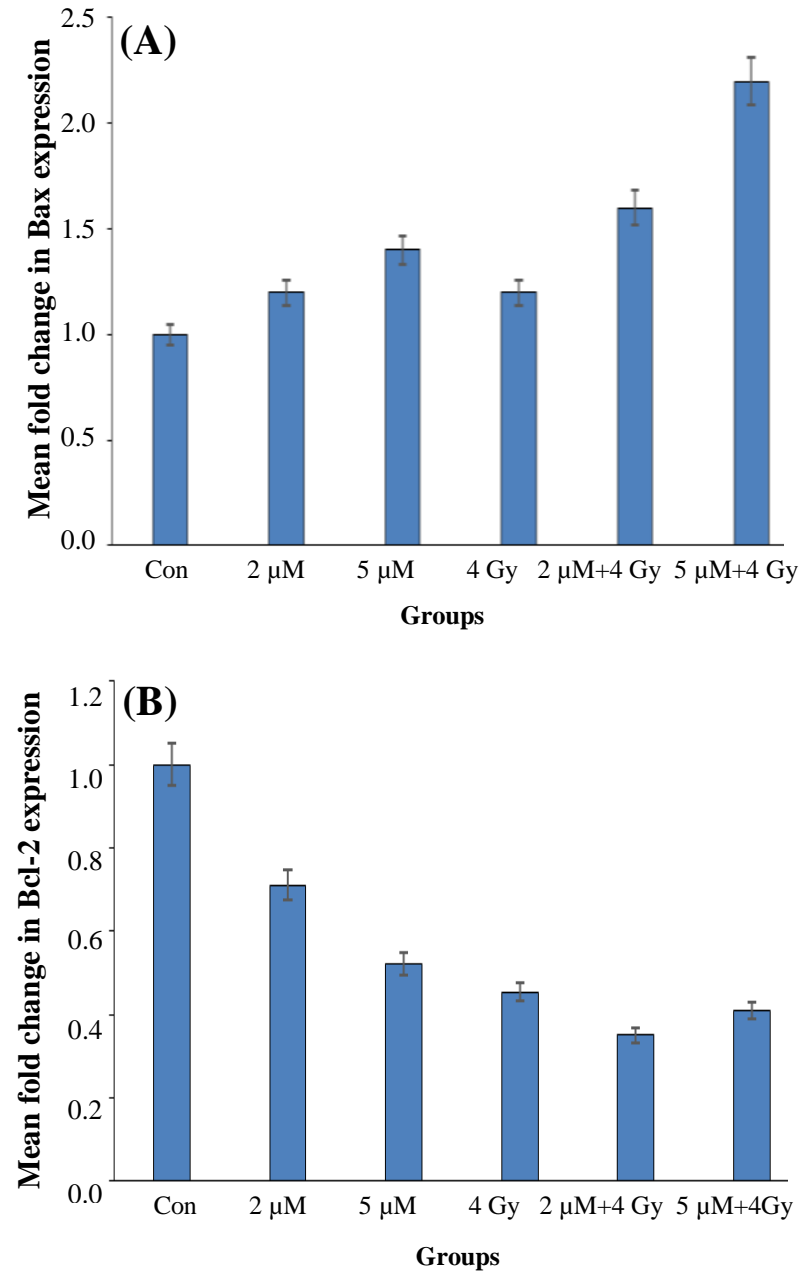

Fig. 4. Expression status of Bax and Bcl-2. (A) Mean foldchange in gene expression level of $B a x$ (A) and $B c l-2$ (B) in U87MG spheroid following treatment by $\mathrm{ATO} \pm \mathrm{IR}$ for one doubling time $(54.7 \mathrm{~h})$. Each bar represents the mean \pm SD of the results of three independent experiments. 

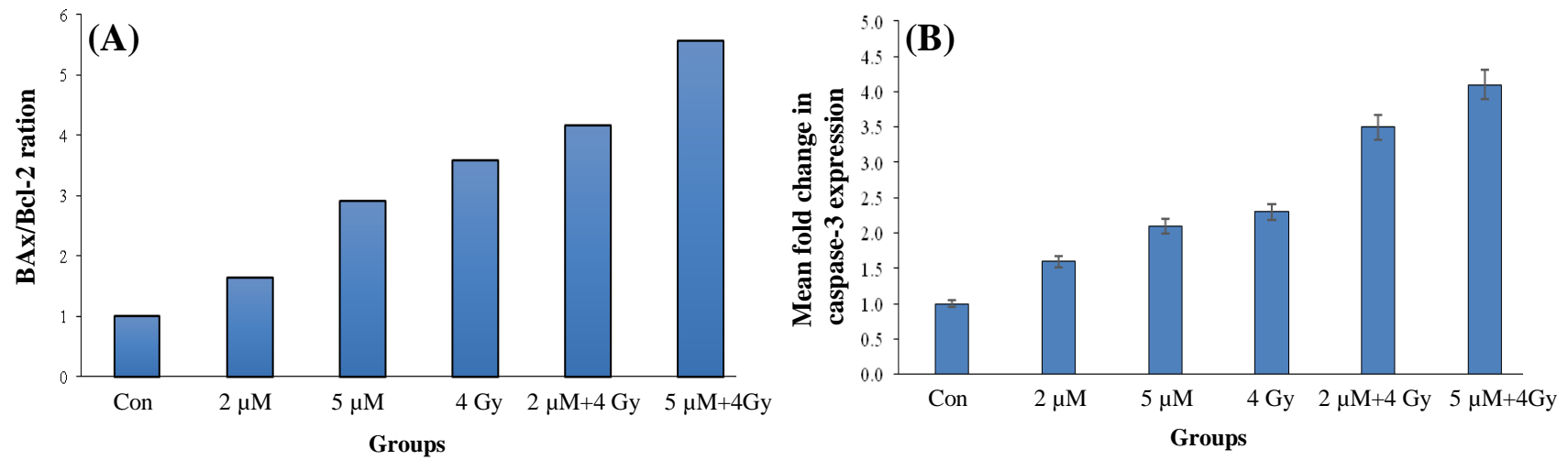

Fig. 5. Expression ratio of $B a x / B c l-2$ and caspase3. Relative fold expression ratio of $B a x / B c l-2$ (A) and mean fold-change in gene expression level of caspase-3 (B) and in U87MG spheroids following treatment by ATO \pm IR for one doubling time (54.7 h). Each bar represents the mean $\pm \mathrm{SD}$ of the results of three independent experiments.

by Fas/Fas ligand composite and intrinsic pathway that is mediated by mitochondria ${ }^{[36]}$. However, the activation of caspase-3 in final step is common between two pathways ${ }^{[37]}$.

The cell viability was assessed using MTT assay. As it is shown in Figure 3, the combination of $5 \mu \mathrm{M}$ ATO with $4 \mathrm{~Gy}$ radiation had the greatest synergistic effect. It is expected that $5 \mu \mathrm{M}$ of ATO arrests more cells in $\mathrm{G} 2 / \mathrm{M}$, the cell sensitive phase to radiation; therefore, the cell survival rate was $47.74 \%$. We also found that the survival rate of cells in treatment condition with 2 $\mu \mathrm{M}$ ATO alone and in combination with IR was $83.56 \%$ and $62.76 \%$, respectively. As mentioned, radiation and ATO induce apoptosis; hence, it can be expected that the administration of high doses of these agents induces more cell death than low doses. Our data in Figure 3 confirmed this claim.

In this study, we focused on the Bax, Bcl-2, and caspase-3 expression that are important biomarkers of the intrinsic pathway of apoptosis. Similar to other investigation ${ }^{[18,38-40]}$, our data showed that ATO has the property to induce the up-regulation of $B a x$ and caspase-3 (1.4 and 2.1folds, respectively) and downregulation of $B c l-2$ (near to 0.5 fold). Therefore, it can be concluded that ATO induces molecular pathway of apoptosis, which confirms our cellular results. Bax affects the permeability of mitochondrial membrane, resulting in cytochrome c leakage. This feature helps recruiting and activation of initiator caspase-9, which induces intrinsic pathway of apoptosis through the activation of caspase-3. In contrast to Bax, Bcl-2 is a pro-survival factor that provides a balance between cell death and survival. As it has been shown in Figure 5A, our finding confirmed that ATO alone (1.64-2.92fold) and synergistically in combination with IR (4.16-5.56fold) disturbs this balance in favor to cell death. Caspase-3 is the other key player that acts at the terminal of apoptosis. According to the expression signature of $B a x / B c l-2$, ATO may activate intrinsic pathway of apoptosis, though caspase-3 is the milestone of both intrinsic and extrinsic pathways. Dizaji et al. ${ }^{[41]}$ have reported that ATO and Silibinin have synergistic effects on human glioblastoma U87MG cell line. The $2-\mu \mathrm{M}$ ATO decreased the expression of $\mathrm{BCl}-2$ and increased the expression of caspas-3, which results in apoptosis. Liu et al. ${ }^{[42]}$ have indicated that ATO and $89 \mathrm{SrCl} 2$ decrease and increase the expression of Bcl-2 and Bax proteins, respectively. Although the results of the present study are closely confirmed Liu's findings, $5 \mu \mathrm{M}$ of ATO+4 Gy did not significantly decrease $\mathrm{Bcl}-2$ expression compared to $2 \mu \mathrm{M}+4 \mathrm{~Gy}$ of ATO group (Fig. 4B).

Our findings demonstrated that ATO increased the expression of Bax gene at the doses of $2 \mu \mathrm{M}$ and $5 \mu \mathrm{M}$ with and without radiation. Nonetheless, combining treatments with $2 \mu \mathrm{M}$ and $5 \mu \mathrm{M}$ ATO with 4 Gy of radiation induced significantly more expressions of

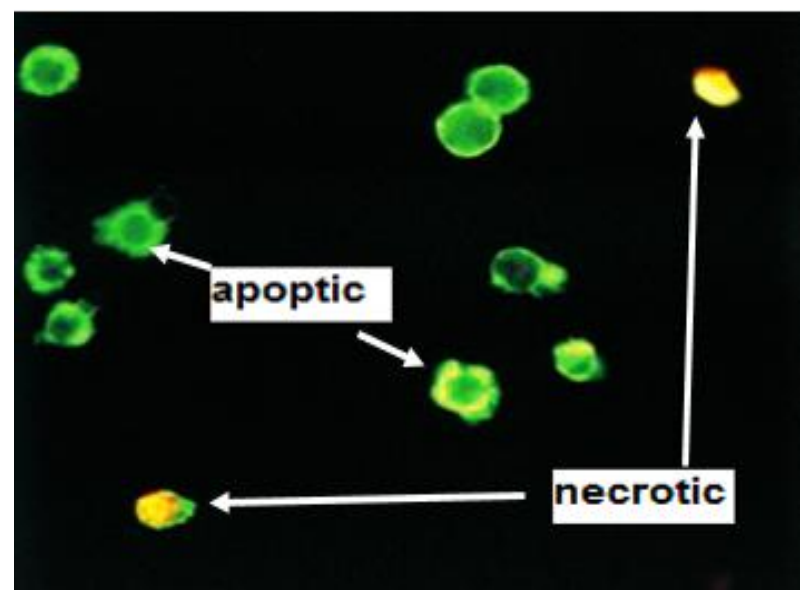

Fig. 6. Cell morphology and apoptosis assay. The apoptotic cells are visible in green and can be differentiated from necrotic cells that stain orange/green. 
Bax gene $(P \leq 0.05$; Fig. 4A), suggesting the synergistic effect of ATO and radiation. Several caspases are thought to mediate the early stages of apoptosis. Among them, caspase- 3 is required for the induction of apoptosis by certain effectors ${ }^{42]}$. As Figure 5B shows, caspase- 3 is up-regulated by both ATO and radiation in a dose-dependent manner; however, the combination therapy more considerably raised caspase-3 expression in comparison to the corresponding doses of ATO or IR alone. These results have been confirmed in the other study ${ }^{[43]}$.

Taken together, the findings of this study revealed that ATO in combination with IR more strongly increased the apoptosis progression in U87MG cells, which in turn results in the cell growth arrest and death. Therefore, combined treatment regimen seems to have more inhibiting efficacy compared to single treatment on U87MG cells. Combined treatment decreased the expression level of $\mathrm{Bcl}-2$ and increased the level of Bax and caspase-3. These molecular findings show that the designed treatment strategy may induce the intrinsic pathway of apoptosis. Our data not only improved our understanding of the cellular and molecular apoptotic effect of ATO alone or in combination with IR but also proposed a possible therapeutic approach to malignant gliomas, which are famous in resistance to pro-apoptotic therapies. Also, in vivo animal studies are required to confirm the potential of ATO for the treatment of GBM cancer.

\section{ACKNOWLEDGEMENTS}

We are grateful to Hamid Abdollahi and Fazel Gorjipour for their helpful advices and contributions during this research. The authors also thank the authorities of Cellular and Molecular Research Center, Iran University of Medical Sciences, Tehran, Iran for the financial support of this project under Grant 25218.

CONFLICT OF INTEREST. None declared.

\section{REFERENCES}

1. Samadian H, Hosseini-Nami S, Kamrava SK, Ghaznavi $\mathrm{H}$, Shakeri-Zadeh A. Folate-conjugated gold nanoparticle as a new nanoplatform for targeted cancer therapy. Journal of cancer research and clinical oncology 2016; 142(11): 2217-2229.

2. Young RM Jamshidi A1, Davis G1, Sherman JH. Current trends in the surgical management and treatment of adult glioblastoma. Annals of translational medicine 2015; 3(9): 121.

3. Stewart, B. and C.P. Wild, World cancer report 2014. World, 2015.
4. Kohler BA, Ward E, McCarthy BJ, Schymura MJ, Ries LA, Eheman C, Jemal A, Anderson RN, Ajani UA, Edwards BK. Annual report to the nation on the status of cancer, 1975-2007, featuring tumors of the brain and other nervous system. Journal of the national cancer institute 2011; 103(9); 714-736.

5. Gallego, O., Nonsurgical treatment of recurrent glioblastoma. Current Oncology, 2015. 22(4): p. e273.

6. Van Meir EG, Hadjipanayis CG, Norden AD, Shu HK, Wen PY, Olson JJ. Exciting new advances in neuro-oncology: the avenue to a cure for malignant glioma. CA: a cancer journal for clinicians 2010. 60(3): p. 166-193.

7. Argyriou AA, Antonacopoulou A, Iconomou G, Kalofonos HP. Treatment options for malignant gliomas, emphasizing towards new molecularly targeted therapies. Critical reviews in oncology/hematology 2009; 69(3): 199-210.

8. Sheline GE, Wara WM, Smith V. Therapeutic irradiation and brain injury. International journal of radiation oncology biology physics 1980: 6(9): 12151228.

9. DeVITTA V, Vincent TD, Teodore SL, Rosenberg SS. Principles of Surgical Oncology: Cancer: Prenciples and Practice of Oncology. $8^{\text {th }}$ ed. USA: Walters Kluwer/Lippincott Williams \& Wilkins; 2008.

10. Ho SY1, Wu WJ, Chiu HW, Chen YA, Ho YS, Guo HR, Wang YJ. Arsenic trioxide and radiation enhance apoptotic effects in HL-60 cells through increased ROS generation and regulation of JNK and p38 MAPK signaling pathways. Chemico-biological interactions 2011; 193(2): 162-171.

11. Kumar, P Gao Q, Ning Y, Wang Z, Krebsbach PH, Polverini PJ. Arsenic trioxide enhances the therapeutic efficacy of radiation treatment of oral squamous carcinoma while protecting bone. Molecular cancer therapeutics 2008. 7(7): p. 2060-2069.

12. Raffoux E, Rousselot P, Poupon J, Daniel MT, Cassinat B, Delarue R, Taksin AL, Réa D, Buzyn A, Tibi A, Lebbé G, Cimerman P, Chomienne C, Fermand JP, de Thé H, Degos L, Hermine O, Dombret H. Combined treatment with arsenic trioxide and all-trans-retinoic acid in patients with relapsed acute promyelocytic leukemia. Journal of clinical oncology 2003; 21(12): 2326-2334

13. Cohen MH, Hirschfeld S, Flamm Honig S, Ibrahim A, Johnson JR, O'Leary JJ, White RM, Williams GA, Pazdur R. Drug approval summaries: arsenic trioxide, tamoxifen citrate, anastrazole, paclitaxel, bexarotene. The oncologist 2001; 6(1): 4-11.

14. Chiu HW, Chen YA, Ho SY, Wang YJ. Arsenic trioxide enhances the radiation sensitivity of androgendependent and-independent human prostate cancer cells. PloS one 2012; 7(2): e31579.

15. Miller WH Jr1, Schipper HM, Lee JS, Singer J, Waxman S. Mechanisms of action of arsenic trioxide. Cancer research 2002; 62(14): 3893-3903.

16. Taylor RC, Cullen SP, Martin SJ. Apoptosis: controlled demolition at the cellular level. Nature reviews molecular cell biology 2008; 9(3): 231-241. 
17. Dewey WC1, Ling CC, Meyn RE. Radiation-induced apoptosis: relevance to radiotherapy. International journal of radiation oncology biology• physics 1995; 33(4): 781-796.

18. Chen GQ, Zhu J, Shi XG, Ni JH, Zhong HJ, Si GY, Jin XL, Tang W, Li XS, Xong SM, Shen ZX, Sun GL, Ma J, Zhang P, Zhang TD, Gazin C, Naoe T, Chen SJ, Wang ZY, Chen $\mathrm{Z}$. In vitro studies on cellular and molecular mechanisms of arsenic trioxide (As2O3) in the treatment of acute promyelocytic leukemia: As2O3 induces NB4 cell apoptosis with downregulation of Bcl2 expression and modulation of PML-RAR alpha/PML proteins. Blood 1996; 88(3): 1052-1061.

19. Chen YC, Lin-Shiau SY, Lin JK. Involvement of reactive oxygen species and caspase 3 activation in arsenite-induced apoptosis. Journal of cellular physiology 1998; 177(2): 324-333.

20. Huff J, Waalkes M, Nyska A, Chan P. Apoptosis and growth inhibition in malignant lymphocytes after treatment with arsenic trioxide at clinically achievable concentrations. Journal of the national cancer institute 1999; 91(19): 772-778.

21. Lam HK, Li K, Chik KW, Yang M, Liu VC, Li CK, Fok TF, Ng PC, Shing MM, Chuen CK, Yuen PM. Arsenic trioxide mediates intrinsic and extrinsic pathways of apoptosis and cell cycle arrest in acute megakaryocytic leukemia. International journal of oncology 2005; 27(2): 537-545.

22. Schmittgen TD, Livak KJ. Analyzing real-time PCR data by the comparative CT method. Nature protocols 2008; 3: 1101-1108.

23. AFSHAR MAA, Moloudi K, Amirrashedi M, Rashidi $\mathrm{M}$, Samadian ranjbar H. A brief review on polymer and protein based nanotheranostics. International journal of biology pharmacy and allied sciences 2015; 5(1): 112128.

24. Goldsmith MA, Carter SK. Glioblastoma multiformeA review of therapy. Cancer treatment reviews 1974; 1(2): 153-165.

25. Adamson C, Kanu OO, Mehta AI, Di C, Lin N, Mattox AK, Bigner DD. Glioblastoma multiforme: a review of where we have been and where we are going. Expert opinion on investigational drugs 2009; 18(8): 10611083.

26. Probert JC, Parker BR. The effects of radiation therapy on bone growth. Radiology 1975; 114(1): 155-162.

27. Chiu HW, Ho SY, Guo HR, Wang YJ. Combination treatment with arsenic trioxide and irradiation enhances autophagic effects in U118-MG cells through increased mitotic arrest and regulation of PI3K/Akt and ERK1/2 signaling pathways. Autophagy 2009; 5(4): 472-483.

28. Ding, D, Lim KS, Eberhart CG. Arsenic trioxide inhibits Hedgehog, Notch and stem cell properties in glioblastoma neurospheres. Acta neuropathologica communications 2014; 2: 31.

29. Cai X, Yu Y, Huang Y, Zhang L, Jia PM, Zhao Q, Chen Z, Tong JH, Dai W, Chen GQ. Arsenic trioxide-induced mitotic arrest and apoptosis in acute promyelocytic leukemia cells. Leukemia 2003; 17(7): 1333-1337.
30. Vuky J, Yu R, Schwartz L, Motzer RJ. Phase II trial of arsenic trioxide in patients with metastatic renal cell carcinoma. Investigational new drugs 2002; 20(3): 327330.

31. Brown JM, Attardi LD. The role of apoptosis in cancer development and treatment response. Nature reviews cancer 2005; 5(3): 231-237.

32. Brown, E., C.G. Yedjou, and P.B. Tchounwou. Cytotoxicity and oxidative stress in human liver carcinoma cells exposed to arsenic trioxide (HepG2). in Metal ions in biology and medicine: proceedings of the... International Symposium on Metal Ions in Biology and Medicine held... = Les ions metalliques en biologie et en medecine ...:Symposium international sur les ions metalliques. 2008. NIH Public Access.

33. Han YH, Kim SZ, Kim SH, Park WH. Arsenic trioxide inhibits growth of As4.1 juxtaglomerular cells via cell cycle arrest and caspase-independent apoptosis. American journal of physiology-renal physiology 2007; 293(2): F511-F520.

34. Conradt, B. and D. Xue, Programmed cell death. 2005.

35. Ouyang L, Shi Z, Zhao S, Wang FT, Zhou TT, Liu B, Bao JK. Programmed cell death pathways in cancer: a review of apoptosis, autophagy and programmed necrosis. Cell proliferation 2012; 45(6): 487-498.

36. Ghobrial IM, Witzig TE, Adjei AA. Targeting apoptosis pathways in cancer therapy. CA cancer journal for clinicians 2005; 55(3): 178-194.

37. 42Elmore S. Apoptosis: a review of programmed cell death. Toxicologic pathology 2007; 35(4): 495-516.

38. Perkins C, Kim CN, Fang G, Bhalla KN. Arsenic induces apoptosis of multidrug-resistant human myeloid leukemia cells that express Bcr-Abl or overexpress MDR, MRP, Bcl-2, or Bcl-xL. Blood 2000; 95: 10141022.

39. Chiu HW, Lin JH, Chen YA, Ho SY, Wang YJ. Combination treatment with arsenic trioxide and irradiation enhances cell-killing effects in human fibrosarcoma cells in vitro and in vivo through induction of both autophagy and apoptosis. Autophagy 2010; 6(3): 353-365.

40. Liu Q, Hilsenbeck S, Gazitt Y. Arsenic trioxide-induced apoptosis in myeloma cells: p53-dependent G1 or G2/M cell cycle arrest ,activation of caspase- 8 or caspase-9, and synergy with APO2/TRAIL. Blood 2003. 101(10): 4078-4087.

41. Dizaji MZ, Malehmir M, Ghavamzadeh A, Alimoghaddam K, Ghaffari SH. Synergistic effects of arsenic trioxide and silibinin on apoptosis and invasion in human glioblastoma U87MG cell line. Neurochemical research 2012; 37(2): 370-380.

42. Liu H, Tao X, Ma F, Qiu J, Wu C, Wang M. Radiosensitizing effects of arsenic trioxide on MCF-7 human breast cancer cells exposed to 89strontium chloride. Oncology reports 2012; 28(5): 1894-1902.

43. Liang XQ, Cao EH, Zhang Y, Qin JF. P53-induced gene 11 (PIG11) involved in arsenic trioxide-induced apoptosis in human gastric cancer MGC-803 cells. Oncology reports 2003; 10(5): 1265-1269. 